\title{
Manual Anarquista de Preparación Artística
}

Luis Camnitzer é artista uruguaio sediado em Nova York. Representou o Uruguai na Bienal de Veneza em 1988 e participou da Documenta XI, em Kassel, 2002. Mais recentemente, em 2018-2019, ele teve uma exposição retrospectiva no Museu Reina Sofía, em Madri. É autor de diversos livros sobre arte e educação. <camnitzer1@gmail.com>
Resumen Conferencia impartida por Luis Camnitzer en la Escuela de Bellas Artes del Perú en 2019.

Palabras clave Anarquía, Arte, Contemporáneo, Educación.

\section{Anarchist Manual of Artistic Preparation}

Abstract Lecture given by Luis Camnitzer at the Peruvian School of Fine Arts in 2019.

Keywords Anarchy, Art, Contemporary, Education.

\section{Manual Anarquista de Preparação Artística}

Resumo Palestra proferida por Luis Camnitzer na Escola de Belas Artes do Peru em 2019.

Palavras chave Anarquia, Arte, Contemporâneo, Educação.o. 
Yo me eduqué en el siglo pasado en una época en que estaban de moda los manifiestos. Fiel a la tradición que me educó, cada tanto me salgo con algún manifiesto propio y el siguiente manual que paso a leer es un ejemplo:

\section{Manual Anarquista de Preparación Artística}

- Todo lo que está en orden tiene que ser desordenado para entender la razón que informa su orden.

- Elartetieneque ser utilizado como uninstrumentopara el aprendizaje de los demás y no para adoctrinarlos.

- Para evitar abusos y poder responsabilizarse de su obra, el artista tiene que identificar en donde se ubica el poder.

- El poder puede estar en uno mismo, en la obra, o en el público, y hay que tratarlo de acuerdo con su ubicación.

- Las recetas artísticas introducen falsos órdenes y no desarrollan la conciencia, sino que la erosionan.

- La obra de arte debe activar la creación de los demás, no frenarla.

- Endulzar las obras de arte no mejora su gusto.

- El arte placentero es demagogia.

- Si la forma no apoya el contenido narrativo y no se integra con ella, la obra de arte es hipócrita.

- El arte ordenado está para ser desordenado y reordenarlo mejor.

- Todos tenemos el derecho al desorden, siempre que sea constructivo.

- La verdad no es, ni una cosa fija, ni una propiedad privada del artista.

- Generalmente, las obras de arte de los demás son tan buenas o mejores que las de uno.

- La fama en el arte no es sinónimo de calidad.

- El arte competitivo ayuda a fijar los precios, pero destruye la cultura.

- El que se venda o no se venda la obra no tiene nada que ver ni con la obra ni con el público.

- Cuanto menos visible la autoría del artista, más espacio queda libre para el cambio social.

- El fin no justifica los medios, por lo tanto, la expresión del material merece tanto respeto como todo lo demás.

- La transparencia no solamente es material sino es también un concepto y forma parte de la rendición de cuentas del artista. 
- Sin transparencia no hay arte. Solamente hay magia de pacotilla y el consiguiente abuso de poder.

- La mirada crítica es tanto parte de la creación de la obra como lo es de su recepción.

- La mirada crítica a veces es más importante que la obra.

- El autor tiene que ser su propio público primero, para que luego todo el público llegue a ser autor.

- El artista, como todos los demás, necesita libertad de pensamiento y de expresión, pero no por eso es un ciudadano con coronita.

- El efecto final de una obra exitosa tiene que ser que el público termine educando al público.

El manual obviamente está dirigido al artista profesional o a quien lo va a ser, y refleja una serie de dudas sobre la formación que, sin muchos cuestionamientos, lleva a la profesionalización. A esta altura tengo que confesar que también tengo mis dudas sobre el significado y la importancia de la profesionalización del artista. No es que quiera negar la existencia de las escuelas de arte o el derecho a ser un artista profesional. Pero en el día de hoy, estamos trabajando en el marco de un sistema educativo muy particular que pienso que no solamente es anacrónico sino también antisocial. Como en todas las profesiones, se entrena al educando para sobrevivir dentro de un mercado en lugar de educarlo para contribuir a la maduración individual y a la construcción de una cultura colectiva.

Esta prioridad del entrenamiento para el mercado nos hace aceptar, como si fuera una pauta normal, la noción que el artista es un individuo que tiene que establecerse con una marca comercial llamada "originalidad". Y esa marca, obligadamente, tiene que competir con las marcas comerciales de los otros artistas para así poder establecerse. Una consecuencia de esto es que, en lugar de construir cultura, se favorecen los mitos individuales y la fabricación de íconos deseables y adquiribles. La otra consecuencia es que, después de largos años invertidos en estudiar, las probabilidades de supervivencia económica del graduado son mínimas. Esto obliga a cuestionar un poco el sentido que pueda tener este tipo de entrenamiento. Quizás sea hora de alterar rumbos y convertir la educación del artista en una educación integral, en algo que sea aplicable a cualquier actividad y que esté integrada con ella. Este cambio en parte ya está ocurriendo en la cultura empresarial. El problema, sin embargo, es que allí esta creatividad se produce en forma limitada. Si bien genera lucro, no genera conocimientos.

Con esto de generar conocimientos en mente, el arte es mucho más importante que como mero medio de producción. Pero aún si, tal como se hace hoy, aceptamos al arte como un campo de producción y de profesio- 
nalización especializada, todavía tenemos que hay fallas en la preparación del estudiante. Uno de los puntos que me parecen claves en la formación del artista en ese sentido, y que en parte me llevaron a escribir el manual/ manifiesto, es la extraña ausencia de los temas éticos relacionados a la expresión artística y sus consecuencias.

Desde Hipócrates en adelante, la ética fue parte de la educación médica. Esto se justificó, apropiadamente, por las intervenciones que el médico hace en el cuerpo ajeno. Entretanto, el arte interviene en las mentes y las emociones ajenas, y a veces también en los cuerpos, y sin embargo allí la ética no se discute. No es que exista la posibilidad de un código firme de comportamiento para el artista, ya que éste terminaría siendo un instrumento de censura. Pero la producción del arte tiene implicancias éticas comerciales y ecológicas las cuales, al servir a una estructura de poder económico, son pasibles de tener consecuencias sociales. Y también, al trabajar con la comunicación, el artista se enfrenta a distintas alternativas con respecto a la coherencia, a la credibilidad y a los intereses que sirven los mensajes.

Aun sin recetas que guíen el comportamiento del artista, parece importante que este se enfrente a los temas y las decisiones que trascienden su narcisismo. Son esos temas los que pueden llevarlo a la politización responsable. Son temas que obligan a pensar en que sucede más allá de la presencia de la obra y que efecto tendrá esta en el espectador, el propietario, o el colectivo social. Obligan a justificar el acto de comunicación artística más allá de la satisfacción de ser autor y hace consciente que la obra es nada más que un eslabón en la cadena de las relaciones sociales.

Esta definición nos describe el espacio en el cual la profesión de artista y la del educador se encuentran e integran, un espacio negado por el profesionalismo mercantil. En esta formación profesionalista, el artista se preocupa más por el mercadeo que por la comunicación. La actividad se concentra en tratar de imponerse en el campo del consumo en lugar de fomentar un proceso de aprendizaje y activar la creatividad del público. La relación que se establece entre el artista con el público termina siendo distorsionada por el valor monetario atribuido.

Si pensamos en cultura en lugar de los triunfos personales, nos damos cuenta de que más allá que la interacción del artista con el público es la relación del público con el público la que al final de cuentas interesa más. Por lo tanto, el asunto de las "relaciones" también tiene importancia en las áreas pedagógicas. En nuestra sociedad adoramos religiosamente los datos, los íconos y los objetos. Basamos nuestro sistema económico en ellos y suponemos que el conocimiento está constituido por su acumulación. Pero el conocimiento bien entendido trata menos de los datos que de cómo articulamos las configuraciones que nos permiten organizar el universo. Los datos son útiles, pero sintomáticos y secundarios. No son algo absoluto: son nada más que unos puntos de referencia pasajera. El conocimiento real está basado en configuraciones efímeras que están sujetas a nuestro poder de 
articulación y cambio. A pesar de ello, el sistema educativo sigue llevándonos a aprender datos en lugar de ayudarnos a configurarlos. Es como memorizar un mapa en lugar de tratar del concepto "mapa" y el acto de mapear. Los mapas, poco después de memorizados terminan siendo anacrónicos.

Los mapas y el mapeo constituyen una analogía pertinente para ayudarnos en una aproximación al arte, aunque las disciplinas académicas y las profesiones en general también pueden ser discutidas como mapas. El mapa nos permite partir de un punto A y llegar a un punto B. El problema es que después de un tiempo el punto A o el punto B, o ambos dos, dejan de existir y nos quedamos en babia. Los desempleos y los cambios de empleo en nuestra sociedad están en constante y creciente aumento, cortando la vida de los mapas que nos enseñan. Seguimos así educando en base a profesiones cerradas, lo que nos obliga llegado el momento a un reentrenamiento que tiene cada vez que partir de cero.

La ironía es que las artes, las disciplinas menos respetada en el mundo académico, son las que mejor nos equipan para ser buenos cartógrafos. Las obras de arte, no importa de qué período histórico o en que medio, pueden ser vistas como simples mapas diseñados para recorrer y descubrir conocimientos. El artista en esto es esencialmente un creador de mapas que aprende nuevas geografías durante la creación. Si los mapas del artista son buenos, estos nos ayudan no solamente a crear mapas nuevos, sino también a mapear por nuestros propios medios.

La analogía del mapa es una entre varias analogías posibles para entender el funcionamiento del arte. Hay muchas otras. Podemos referirnos también a la creación de juegos. Cuando es el autor del juego, el artista crea las reglas. Cuando el juego ya fue creado por otros, el artista trata de ser un jugador maestro. Luego el espectador entiende cual es el juego y lo juega junto con el artista. Luego hay otra analogía, que es la solución de problemas. Allí el artista formula un problema interesante y busca solucionarlo y compartir la solución. El espectador entonces ubica el problema y trata de recrear la solución ofrecida o encontrar otra.

Lo que es interesante en estas analogías es que trascienden y profundizan las formas tradicionales de mirar una obra. Ya no se trata de si la obra gusta o no, o si está bien o mal hecha. Las analogías obligan, tanto al artista como al público, a tratar al arte como una forma de conocimiento. Una vez que el arte es aceptado como conocimiento podemos decidir si nos aporta algo o no, si aprendemos algo nuevo y si nos empodera para seguir aprendiendo.

Mapas, juego, o formulación y solución de problemas, en cualquiera de las tres analogías la presentación, la situación jerárquica competitiva y el valor monetario de una obra claramente pertenecen a un campo completamente distinto al que le corresponde a la contribución al conocimiento. Que Newton, o Einstein, hayan tenido buena letra no tiene importancia. No importa si sus obras contribuyeron a la caligrafía. Importa que cosas contribuyeron al conocimiento. Si discutimos a un Picasso o similar, la caligrafía o forma de manejar el pincel adquieren un poco más de importancia ya que es algo inherente al medio utilizado. Pero en términos culturales importa 
mucho más si la obra de arte afectó nuestra forma de ver y de conocer. 0 sea, si cambió nuestra forma de hacer mapas, de cómo creamos y jugamos juegos, o que problemas proponemos y como los solucionamos. Ya no se trata de que cosa concreta se produjo, sino de que cosas podemos hacer gracias a ver lo que se produjo. Mientras esos objetos pueden tener un precio, los permisos que nos dan no lo tienen. Entonces, de acuerdo con que analogía tomamos, el poder hacer nuestros mapas, el jugar nuestros juegos o el solucionar nuestros problemas, todo esto es algo suficientemente intangible como para evadir las reglas del mercado. Con el arte entendido como conocimiento, el poder se sale del objeto y pasa a manos del público. Lo que queda con un precio es una cáscara.

El manifiesto que leí al principio surgió del arte, o mejor, del hecho que yo sea artista. Pero es claro que sus ideas sirven para cualquier cosa, y esto no es algo casual. Si el arte es un método para adquirir, articular y expandir conocimientos, la profesionalización artística es nada más que uno de los niveles dentro de un proceso continuo que se produce en varios niveles. Cabe entonces preguntarse en donde está exactamente la frontera que separa al no-artista del artista, y porqué esa frontera está allí. Si tengo que precisar el lugar en el sistema presente, diría que esa frontera está al final del jardín de infantes y que está allí impuesto por gente que no son precisamente los niños.

El niño preescolar tiene permiso para jugar y descubrir libremente. Es decir, tiene libertad para hacer sus mapas, crear y jugar sus juegos, y para formular y resolver problemas. Combina cosas no combinables y arma sus propios órdenes hasta que la aplicación en el mundo cotidiano le informa cuales cosas son posibles y cuales no lo son. En cuanto el niño entra en la escuela primaria, a menos que sea una escuela privada y costosa que usa las pedagogías constructivistas, la vida se reduce a solamente aquello que es posible y práctico. Lo imposible se descarta, y lo que es posible se contabiliza con números y se compara con otras cosas también contadas con números. La vida se convierte en algo cuantificable en donde "más" es sinónimo de "mejor" y en donde la educación pasa a ser entrenamiento para, en un futuro construido sobre un pasado conocido, poder sobrevivir en la economía del mercado.

Es recién después de sobrevivir dentro del sistema escolar una década o más, que se ofrece la posibilidad de volver a engranar con la fantasía infantil. Es el momento cuando el estudiante decide entrar en la escuela de arte y se le permite el ingreso a ella. Para recibir el permiso de ingreso, la escuela tiene que decidir que el candidato tiene esa cualidad inmedible llamada "talento". Y si se considera que tiene una cantidad suficiente, los estudios allí vuelven a ser cuantificables. El educando es declarado artista después de una cantidad determinada de años y de créditos, los cuales se documentan en un diploma. Entretanto, la experiencia que se tuvo en la escuela de arte consistió en aprender una serie de técnicas, en --con suerte-enterarse que es; o que hicieron otros artistas y cómo funciona el mercado, y posiblemente en tener tiempo para fantasear en caso de que esto sea una actividad de interés. 
Es claro que la frontera entre artista y no-artista no solamente es arbitraria, sino también dañina. Por definición, las fronteras son instrumentos de fragmentación, separan en lugar de unir, y sirven para definir recipientes cerrados en lugar de crear campos de conexiones. Son, por lo tanto, eminentemente antipedagógicas. La solución, al menos desde mi punto de vista, es la eliminación de las fronteras en la educación y la formación de educandos, acentuando en cambio la habilidad de configurar y de hacer conexiones. Muchos de los que estudian arte ya eran artistas antes de ingresar a la escuela. Y muchos egresados de las escuelas de arte siguen no siendo artistas. El resultado no depende de los conocimientos adquiridos, no por los conocimientos mismos sino por los prejuicios educacionales con los cuales son puestos a disposición para su adquisición.

Al hablar de la "adquisición de conocimientos", que es la forma normal de referirnos al proceso educacional, presumimos que el conocimiento es ofrecido en una especie de tienda. Uno va y lo compra: "por favor me da un kilo y medio de conocimientos" “¿Cuánto le debo?" o: "Por favor me da 120 créditos de educación" que no es muy distinto, y que tiene un precio fijo de acuerdo con la institución. El concepto funciona en términos de la economía de las escuelas, pero es menos útil cuando se discute la formación de una persona. Olvida que el proceso de conocer es autodidacta, continuo, no localizado físicamente en el espacio, y permanente en el tiempo. Cuando no es así y viene en paquetes, lo es porque hay interferencias que obstaculizan la educación en lugar de ayudarle.

Una respuesta posible a todo esto, es que debemos eliminar todas las disciplinas y las especializaciones, los mercados, las leyes, y, por supuesto, también el dinero. Pero la veo un poco difícil de lograr, y me temo que no hay una solución verdaderamente rápida para el problema. En cambio, hay más posibilidad en las soluciones lentas, aquellas que consisten en educar a educar. Estas provienen de los dos extremos: de la universidad para abajo y de la escuela primaria para arriba.

De la universidad para abajo consiste en crear una nueva conciencia tanto en la formación de los artistas como de los profesionales en general. Los profesionales tienen que comenzar a entender que la especialización no funciona correctamente si se efectúa como si hubiera un vacío a su alrededor, y aun menos si se encierra en el contexto del pensamiento cuantitativo y tecnológico. Cuanto más el mercado neoliberal demanda acentuar solamente los conocimientos prácticos y aplicables, más el estudiantado y el profesorado tienen que combatir esta dinámica y exigir la formación integral que protege el derecho y la habilidad de especular, criticar e imaginar. Esto significa utilizar el arte como una forma de conocimiento integrada a todo lo que se hace y no como una actividad esotérica reservada para los artistas. Este cambio ayudará a que los profesores y maestros de mañana comiencen a revisar todo el sistema pedagógico.

Desde la escuela primaria para arriba la lucha consiste en dar prioridad al aprendizaje continuo, y a permitir pensar en lo imposible y lo ilógico como complementos imprescindibles de lo posible y lo lógico. Consiste 
en promocionar la imaginación sin límites antes de negociar con la realidad de lo posible. Consiste en identificar qué es lo que hace que lo imposible no se pueda realizar, y qué o quién lo impide y por qué. Y con ello tratar de ampliar al máximo el campo de lo posible. Esto no es algo que pueda ser monopolizado por el artista, sino que es una actividad que le pertenece a todo buen ciudadano.

Para terminar, voy a agregar aquí que en su versión original mi manual también incluía algunos consejos prácticos que tomé de mi larga experiencia y que pueden ser de alguna utilidad:

1. Para hacer buenos verticales es mejor dibujarlas desde abajo hacia arriba para tengan cierta estabilidad y que no queden colgadas.

2. Entre la construcción de un cubo y una pirámide, es mejor el cubo, ya que a este también se lo puede poner de costado o patas para arriba.

3. En caso de que a pesar de ello se elija una pirámide, conviene hacer primero la base y dejar el vértice superior para el final.

4. Las obras de mucho peso necesitan de una plataforma fuerte para evitar su colapso. Esto se refiere tanto a lo material como lo teórico.

5. Si no se afila el lápiz cada tanto, el dibujo pierde su nitidez y hay que volver a hacerlo.

$\mathrm{Y}$, por último,

6. La goma de borrar puede corregir los errores, pero no borra la culpa. 